\title{
A Heterogeneous Agent-based Asset Pricing Model and Simulation
}

\author{
Haiying Ren ${ }^{\mathrm{a}}$, Siwei $\mathrm{Li}^{\mathrm{b}}$
}

School of Economics \& Management, Beijing University of Technology, Beijing, China

\begin{abstract}
Behavioral finance models can help to explain several stylized facts in financial markets. As one of the behavioral financial theory, prospect theory describes how 'irrational investors' making decisions under uncertainty. In this paper, we present a heterogeneous agent-based asset pricing model, where parts of investors determine their demand for risky asset using prospect theory utility function. Time series generated from simulation show many stylized facts that can be observed in actual financial markets, such as abnormal distribution of asset returns, volatility clustering and equity premium. We also find that positive correlation between investors' performance and their market share, negative correlation between investors' performance and the loss aversion coefficient under certain market condition.
\end{abstract}

Index Terms: Prospect Theory; Heterogeneous agent models (HAMs); Stylized Facts

(C) 2012 Published by MECS Publisher. Selection and/or peer review under responsibility of the Research Association of Modern Education and Computer Science.

\section{Introduction}

The hypothesis of rational person is one of the basic hypothesizes in modern finance. However, massive empirical analysis and psychology research indicated that people are not rational enough when making decisions in real market, irrational behavior such as herd behavior, disposition effect, loss aversion and overreaction exist. Based on empirical analysis and psychology research, behavior financiers explained some important observed stylized facts in financial time series by relaxing the constraint of the hypothesis.

Heterogeneous agent models (HAMs) are behavioral rather than using a single representative type of rational agents. In HAMs, the market is filled with heterogeneous, boundedly rational agents with different expectation and behaviors. This bottom-up method involves large numbers of interacting agents with rule of thumb trading strategies, and aggregation of simple interactions at the micro level may generate sophisticated structure at the macro level. In early papers by Delong[1], Brock and Hommes[2] and Lux[3].Simple HAMs can generate some important stylized facts, such as high trading volume, sudden crashes, excess volatility, and fat tails. In these HAMs models two typical investor types arise, the fundamentalist and the chartist. They have heterogeneous beliefs, but they are assumed to be constant absolute risk aversion investors (CARA) determining the risky assets demand by maximizing the expected utility function. On the other hand, two kinds

\footnotetext{
* Corresponding author.

E-mail address: ${ }^{a}$ renhaiying@bjut.edu.cn, ${ }^{\mathrm{b}}$ larislee@emails.bjut.edu.cn
} 
of assets exist, the risky assets and the risk free. The risky asset with constant supply whose price is determined by the demand of the investors, and the risk free pays a constant dividend.

In recent research efforts, Carl[4] assume that the investor's optimal risky asset demand depend on wealth, hence CRRA utility instead of CARA utility. Hong[5] adds the short sale constraint to the HAMs. Peter Boswijk[6] estimate an HAMs to annual US price stocks, and the estimation results support the existence of two expectation regimes, the fundamentalist and chartists.

This paper also uses the DeLong, Brock and Hommes framework to construct our HAMs. However, we extend their research by introducing prospect theory to the model, in which investors not only have heterogeneous beliefs but also have heterogeneous utility functions of wealth. Traditionally, investors are be divided into fundamentalists and chartists by their beliefs. While from their preference aspect, investors can be classified into CARA investor and Prospect Theory based investor (PT investor).

In traditional approach, mathematics has been the main tool of analysis. Delong focused on analytical interpretation of the pricing model they derived, explaining the stylized directly from their pricing model. In this paper, we use the Agent-based Computational Economics (ACE) model. This method is flexible when we design the structure of the market and describe the behavior of investors.

The rest of the paper is as follows: Section 2 presents the general concept of prospect theory. Section 3 of the paper is the design of the agent-based model, including the structure of the model and behavior of the investor. Section 4 presents the statistical findings of our computational experiments. Section 5 is the conclusions.

\section{Prospect Theory}

Expected utility theory tell us how to make rational decision to get an optimal results, while prospect theory, describing investors' behavior when they making decisions under uncertainty, is a generalized expected utility theory. Prospect theory is first formally proposed in Kahneman and Tversky, and has been widely accepted by economist now. The application area of the prospect theory includes asset pricing, risk management, and explaining stylized facts. In recent research, for instance, R.Corss[7] introduced herding propensity into an HAM, which results in excess kurtosis and power-law. Roger[8] found that investors acquired for high equity premium because of disposition effect. Barberis[9] designed an model which was influenced by prospect theory can help explain high mean, excess volatility, and predictability of stock returns. Based on Barberis, Zhang[10] explored empirical evidence on the prospect theory for stock markets, adding the break-even effects.

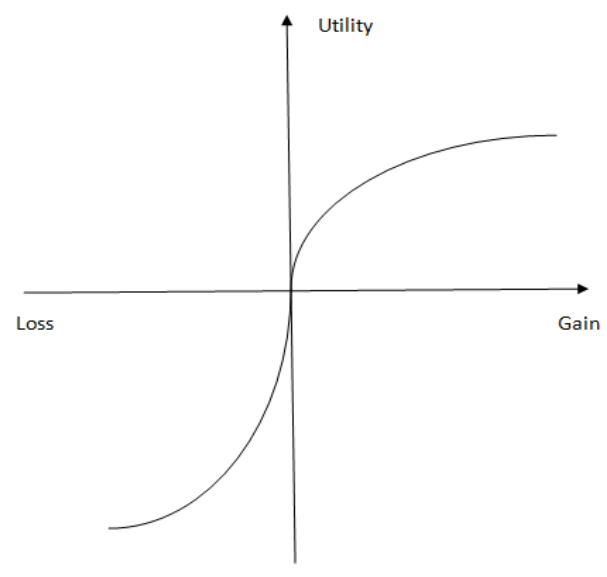

Fig. 1. Prospect theory utility function 
As showed in Fig. 1, prospect theory utility function shaped like "s". The theory describes how individuals evaluate potential losses and gains. There are three main basic features: First, the decision making is based on a reference point. What people care about is the gains or losses from the gamble rather than the absolute wealth level after the gamble. Second, on the right-hand side of the reference point, investors are risk-averse, the same as expected utility function. On the left-hand side, investors are risk-seeking, i.e. they are more willing to take risks to avoid losses. Third, investors are found to be more sensitive about the losses than the gains, this is also called loss aversion.

The prospect theory utility function proposed by Kahneman and Tversky is as follows:

$$
u(x)=\left\{\begin{array}{cl}
(x-v)^{1-\beta}, & x-v \geq 0 \\
-\lambda(v-x)^{1-\beta}, & x-v<0, \text { where } 0<\beta<1, \lambda \geq 1,
\end{array}\right.
$$

$\beta$ is risk averse coefficient, $\lambda$ is loss aversion coefficient, $v$ stands for reference point. After that, revised versions of PT utility function are proposed with some simplifications or extensions. For example, the dogleg shaped PT utility function, the exponential type PT utility function, the log type PT utility function. In our model, we adopt the exponential type PT utility function, which is proposed by Mao, it is as follows:

$$
u(x)=\begin{aligned}
1-e^{-\beta(x-v)}, & x-v \geq 0 \\
-\lambda\left(1-e^{\frac{\beta}{\lambda}(x-v)}\right), & x-v<0
\end{aligned}
$$

where the parameters are the same as KT utility function, but the exponential type is similar to CARA. The reason we take this form utility function is that it's convenient for deriving the demand for risky assets in section 3 .

\section{Heterogeneous Agent Model}

\subsection{Market structure}

The model is infinite-period and dynamic with each investor having an initial wealth of $W_{0}$ and there being only one risky asset in the market, the amount of which is fixed and is constant across time. In each period of time, investors determine how much risky asset $\omega_{i, t}$ they demand according to the utility function (short sale is permitted and there is no transition fee), and the rest of the wealth $1-\omega_{i, t}$ is put in an account with none dividend paid. So, asset return at the end of each period is $R_{t}=\frac{P_{t}-P_{t-1}}{P_{t-1}}$, where $P_{t}$ is the price of the risky asset in period t. So the expectation and variance of the wealth of investor $i$ at the end of period $t$ are as follows:

$$
\begin{aligned}
& E\left(W_{i, t}\right)=\left(1+E\left(R_{t}\right)\right) \omega_{i, t} W_{i, t-1}+\left(1-\omega_{i, t}\right) W_{i, t-1} \\
& D\left(W_{i, t}\right)=D\left(R_{t}\right) \omega_{i, t}^{2} W_{i, t-1}^{2}
\end{aligned}
$$




\subsection{Investors' expectation}

Investors' expectations of the risky asset price are different. From this angle, investors can be classified into two categories, chartists (noise traders) and fundamentalists (sophisticated traders). Chartists believed that the price keeps growing momentum, and the expectation of the risky asset return in period $t$ is:

$$
E\left(R_{i, t}\right)=a_{i} R_{t-1}+b_{i}
$$

Where $a_{i}$ is the momentum coefficient for investor $\mathrm{i}, b_{i}$ is the intercept for investor $\mathrm{i}$.

Fundamentalists know that the price will get back the fundamental level $P_{0}$ in the long run. So the expectation of the risky asset price in period $t$ is:

$$
E\left(P_{t}\right)=v_{i}\left(P_{0}-P_{t-1}\right)+P_{t}
$$

So the expectation of the return is:

$$
E\left(R_{i, t}\right)=\frac{E\left(P_{t}\right)-P_{t-1}}{P_{t-1}}+b_{i}=v_{i} \frac{P_{0}-P_{t-1}}{P_{t-1}}+b_{i}
$$

Where $v_{i}$ is the return speed, $b_{i}$ is the intercept for investor $\mathrm{i}$.

\subsection{Investors' preference}

In our model, the chartists not only have expectations different from the fundamentalists but also have heterogeneous preference among themselves. Investor is assumed to be myopic one-period constant one maximizing an expected utility functions, including the traditional constant absolute risk aversion investors (CARA investors) and prospect theory investors (PT investors). Here, we assume that each end period of time the investors' wealth $W_{i, t}$ is normally distributed, with mean ${ }^{W_{0}}$, and variance $\sigma^{2}$ (constant).

For the CARA investors, they maximize the expected utility function $\max E\left(u_{i, t}\right)=\max E\left(-e^{-\beta W_{i, t}}\right)$, which is equivalent to (See De Long(1990)):

$$
\max \left(E\left(W_{i, t}\right)-\frac{\beta}{2} D\left(W_{i, t}\right)\right)
$$

Put (5) into (1) and (2), and calculate the derivative of (5) for ${ }^{\omega_{i, t}}$, we derive the CARA investors' risky asset demand as follows:

$$
\operatorname{Demand}(C A R A)_{i, t}=\frac{E\left(R_{i, t}\right)}{\beta D\left(R_{i, t}\right)}
$$

For the PT investors, their utility function is: 


$$
u\left(W_{i, t}\right)=\left\{\begin{aligned}
1-e^{-\beta\left(W_{i, t}-W_{0}\right)}, & W_{i, t}-W_{0} \geq 0 \\
-\lambda\left(1-e^{\frac{\beta}{\lambda}\left(W_{i, t}-W_{0}\right)}\right), & W_{i, t}-W_{0}<0
\end{aligned}\right.
$$

Where $\beta, \lambda$ are risk aversion coefficient and loss aversion coefficient respectively, and $W_{0}$ is the reference point. In our model, at the start time of each period, we renew the reference point to the initial level with $10 \%$ probability.

When $W_{i, t} \geq W_{0}$, we get $\max E\left(u_{i, t} \mid W_{i, t} \geq W_{0}\right)$. In the same way with (5), the risky asset demand of the PT investors is (6). When $W_{i, t}<W_{0}$, we get $\max E\left(u_{i, t} \mid W_{i, t}<W_{0}\right)$, which is equivalent to (proof procedure is omitted) :

$$
\max \left(E\left(W_{i, t}\right)+\frac{\beta}{2 \lambda} D\left(W_{i, t}\right)\right)
$$

Put (8) into (1), (2), calculate the derivative of (8) for $\omega_{i, t}$, we derive the PT investors' risky asset demand as follows:

$$
-\frac{E\left(R_{i, t}\right)}{\frac{\beta}{\lambda} D\left(R_{i, t}\right)}
$$

To summarize, the risky asset demand for the PT investor at the time of period is :

$$
\operatorname{Demand}(P T)_{i, t}= \begin{cases}\frac{E\left(R_{i, t}\right)}{\beta D\left(R_{i, t}\right)}, & W_{i, t}-W_{0} \geq 0 \\ -\frac{E\left(R_{i, t}\right)}{\frac{\beta}{\lambda} D\left(R_{i, t}\right)}, & W_{i, t}-W_{0}<0\end{cases}
$$

Formula (10) manifests three main features of the prospect theory: First, the relative wealth levels of the investor influence their decision making, investors make different choice of demand function in the light of the wealth they win or not until the latest period. Second, if $W_{i, t} \geq W_{0}$, an investor makes money until the period $\mathrm{t}-1$, he becomes risk averse, seeking for lower volatility $D\left(R_{i, t}\right)$. If $W_{i, t} \geq W_{0}$, an investor loses money until the period t-1, he becomes risk seeking, ignoring higher volatility $D\left(R_{i, t}\right)$ and seeking for potential return blindly. Third, since the loss aversion coefficient $\lambda>1$, an investor becomes more sensitive to loss when $W_{i, t}<W_{0}$, so the PT investor is loss-averse.

\subsection{Equilibrium Price}

According to 3.3, investors in our model can be divided into three categories because of heterogeneous expectation and preference. There are fundamentalists, CARA chartists, and PT chartists. In each period of 
time, the total demand for risky asset is $D_{t}=\sum_{i=1}^{N}$ Demand $_{i}$. Let $\mathrm{S}$ be the risky asset supply, which is constant. The equilibrium price is determined in period t so as to satisfy $D=\Delta P \cdot S$. So the price formula at the end time of period $t$ is

$$
P_{t}=P_{t-1}+\Delta P=P_{t-1}+D_{t} / S
$$

\section{Numerical Simulation and Analysis}

\subsection{Experiments design}

Based on the HAMs proposed in section 3, we implement the model on the JAVA-SWARM platform. Table 1 is the parameters of the models.

Table 1. HAMs parameter in this paper

\begin{tabular}{cc}
\hline Names of parameters & Value \\
\hline Number of investor N & 1000 \\
Simulation times $\mathrm{T}$ & 5000 \\
Initial price $P_{0}$ & 100 \\
Volatility of return $\sigma^{2}$ & 0.002 \\
Shares S & 100000 \\
The proportion of CARA chartists & $60 \%$ \\
The proportion of PT chartists & $30 \%$ \\
The proportion of fundamentalists & $10 \%$ \\
Momentum coefficient a & range $(0.5,1)$ \\
Interception b & range $(-0.5,0.5)$ \\
Return speed v & range $(0,0.02)$ \\
Risk aversion coefficient $\beta$ & 0.12 \\
Loss aversion coefficient $\lambda$ & 2.25 \\
Initial reference point $W_{0}$ & range $(800,1200)$ \\
\hline
\end{tabular}

\subsection{Statistical features}

The contrast and analysis between the time series of the simulation and the SSEC, SZCI log daily return is showed in table 2(From 2000.6.1 to 2010.6.1). First, JB statistic shows that time series from both simulation and field market refuse the normal distribution, and their kurtosis is larger than 3. So, our model and the filed market both generate the fat tails and high kurtosis. Second, the Dickey-Fuller tell us that both the model and field market generate asset return series, which is stationary.

\subsection{Volatility Clustering}

Volatility clustering is one of the stylized facts of finance time series, which shows the heteroskedasticity of the volatility. As showed in Fig. 2(DF is short for Dickey-Fuller), from the square of the return, it manifests the volatility clustering obviously. The ARCH-LM test also showed that ARCH effect is remarkable on all three series. 
Table 2. Statistic features of risky asset return

\begin{tabular}{ccccccc}
\hline Mean & Variance & Skewness & Kurtosis & JB & DF \\
\hline Shanghai & 0.00 & 0.017 & -0.123 & 6.895 & 1538.150 & -48.795 \\
Shenzheng & 0.00 & 0.018 & -0.16 & 6.270 & 1089.824 & -47.177 \\
Simulation & 0.00 & 0.008 & -0.055 & 4.235 & 320.180 & -43.449 \\
\hline
\end{tabular}

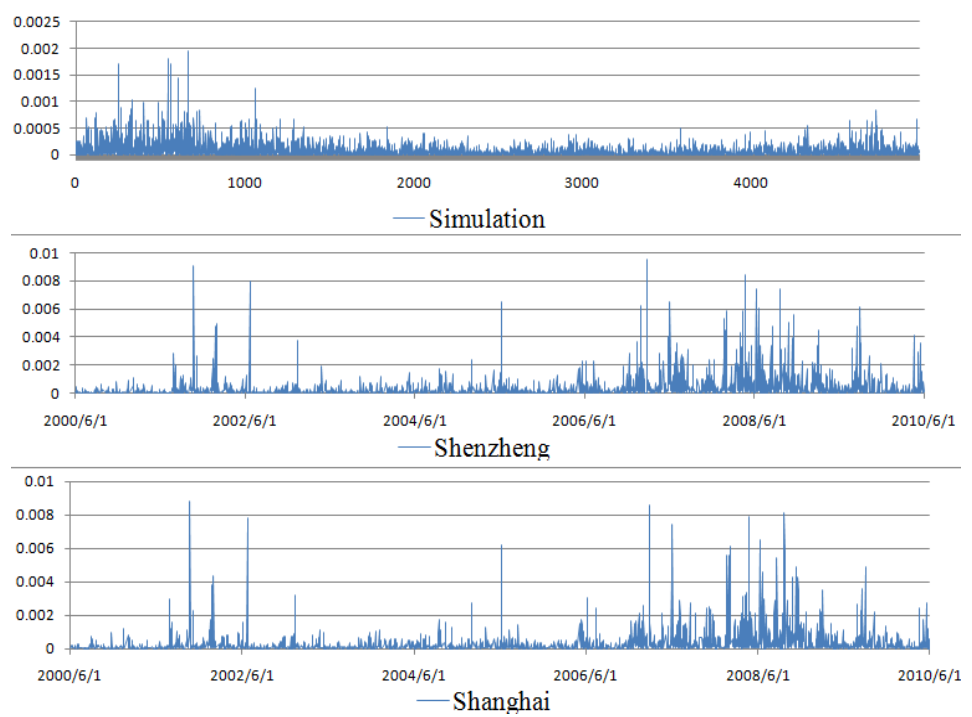

Fig. 2. Square of the return of Index

\subsection{Equity premium}

The equity premium puzzle is first proposed by economists Rajnish Mehra and Edward C. Prescott in 1985. They found that in order to reconcile the much higher return on equity stock compared to government bonds in the United States, individuals must have implausibly high risk aversion according to standard economics models. Researchers made some explanations for this stylized fact from several angle of view, including the market liquidity, the equity premium model's drawback, and the market friction requiring more premiums. Barberis found that the loss aversion investors require large premium to put up with the poorly performances of the stock market. Mao showed that when taking people's loss aversion over consumption into consideration, their model is capable of resolving the equity premium puzzle. In our model, the PT investors reflect on people's loss averse attitude toward the wealth change. As showed in Fig. 3, the market equity premium increases with the proportion of the PT investors increases, this shows that the existence of the PT investors is the main reason for the equity premium. 


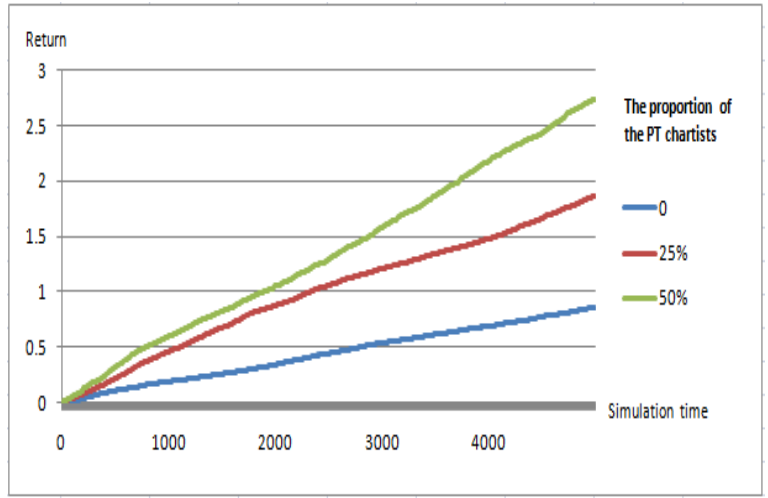

Fig. 3. The risk asset return

\subsection{Investors' performance}

This section, we discuss the performance of the investors when changing some of the parameters of our model.

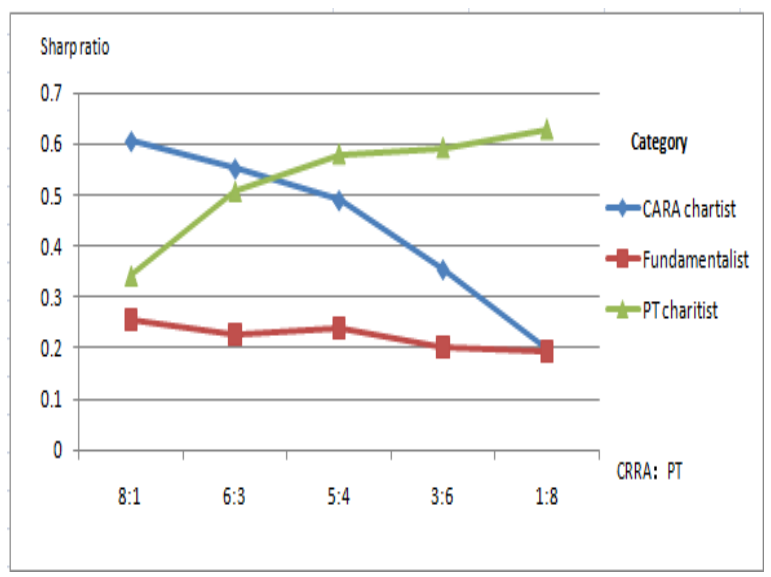

Fig. 4. Sharp ratio of investors

First, we find the key factor that influences the investors' performance is their proportion of the market. If they are the majority, then their performance surpasses others'. If they are the minority, then their performance performed poorer than others'. As showed in Fig. 4, we keep the proportion of the fundamentalists fixed at $10 \%$ of all investors and change the relative ratio of the CARA investors to PT investors from $8: 1$ to $1: 8$. The PT investors' shape ratio increases from 0.3 to 0.6 when proportion increases from $10 \%$ (on the left) to $80 \%$ (on the right).

Second, we investigate how the loss aversion coefficient $\lambda$ influences the investors' performance. After ten replications, we get the average sharp ratio with $\lambda=2$ and $\lambda=4$ respectively. As showed in table 5 , in situation 1, PT chartists occupied the market, and higher loss aversion coefficient reduces the performance of all investors at the $99 \%$ confidence level. While in situation 2, CARA chartists are the majority, and higher loss aversion coefficient reduces the performance of all the chartists, and has litter influence on fundamentalists. 
Table 3. Hypothesis testing for sharp ratio

\begin{tabular}{|c|c|c|c|c|c|c|c|c|c|c|c|}
\hline \multicolumn{4}{|c|}{ CARA chartist } & \multicolumn{4}{|c|}{ Fundamentalist } & \multicolumn{4}{|c|}{ PT chartist } \\
\hline $\begin{array}{c}\text { lambda }= \\
2\end{array}$ & 0.278 & $\begin{array}{c}\text { lambda }= \\
4\end{array}$ & 0.197 & $\begin{array}{c}\text { lambda }= \\
2\end{array}$ & $\begin{array}{c}0.22 \\
4\end{array}$ & $\begin{array}{c}\text { lambda }= \\
4\end{array}$ & $\begin{array}{c}0.14 \\
1\end{array}$ & $\begin{array}{c}\text { lambda }= \\
2\end{array}$ & $\begin{array}{c}0.63 \\
2\end{array}$ & $\begin{array}{c}\text { lambda }= \\
4\end{array}$ & $\begin{array}{c}0.57 \\
1\end{array}$ \\
\hline \multicolumn{4}{|c|}{ H0: SR (4)>=SR(1) } & \multicolumn{4}{|c|}{ H0: SR (4)>=SR(1) } & \multicolumn{4}{|c|}{ H0: SR (4)>=SR(1) } \\
\hline \multicolumn{4}{|c|}{ T value: -7.801 , refuse } & \multicolumn{4}{|c|}{$\mathrm{T}$ value: -10.988 , refuse } & \multicolumn{4}{|c|}{ T value: -4.357 , refuse } \\
\hline \multicolumn{12}{|c|}{ Situation 2: CARA chartist: F } \\
\hline \multicolumn{4}{|c|}{ CARA chartist } & \multicolumn{4}{|c|}{ Fundamentalist } & \multicolumn{4}{|c|}{ PT chartist } \\
\hline lambda $=$ & 0.6048 & lambda $=$ & 0.7340 & lambda $=$ & 0.23 & lambda $=$ & 0.20 & lambda $=$ & 0.32 & lambda $=$ & 0.38 \\
\hline 2 & 7 & 4 & 4 & 2 & 4 & 4 & 8 & 2 & 8 & 4 & 7 \\
\hline \multicolumn{4}{|c|}{ H0: SR $(4)<=S R(1)$} & \multicolumn{4}{|c|}{ H0: SR (4) $>=S R(1)$} & \multicolumn{4}{|c|}{ H0: SR $(4)<=S R(1)$} \\
\hline \multicolumn{4}{|c|}{ T value: 3.395 , refuse } & \multicolumn{4}{|c|}{ T value: -2.144 , not refuse } & \multicolumn{4}{|c|}{ T value: 3.698 , refuse } \\
\hline
\end{tabular}

\section{Conclusion}

This paper introduces the prospect theory into the asset pricing model through a HAMs. The experiments results in several stylized facts, including fat tail, volatility clustering and equity premium. To further step, we investigate the relationship between the investors' performance and the loss aversion coefficient.

In the future, we should investigate the field market and find out how the loss aversion and prospect theory influence investors' performance. Another future direction would be modeling the behavior of actual investors more closely, and enhancing information exchange between agents.

\section{Reference}

[1] J.Bradford De Long, Anrei Shleifer, Lawrence H. Summers, Rober J.Waldmann, "Noise trader Risk in financial market," Journal of political economy, vol.98, 1990, pp.703-738.

[2] William A. Brock, Cars H. Hommes, "Heterogeneous beliefs and routes to chaos in a simple asset pricing model," Journal of economic dynamic and control, vol.22, 1998, pp.1235-1274.

[3]Lux, T, "The socio-economic dynamics of speculative markets: interacting agents, chaos, and the fat tails of return distribution,” Journal of Economic Behavior \& Organization, vol.33, 1998, pp.143-165.

[4] Carl Chiarella, Roberto Dieci, Laura Gardini, "Asset price and wealth dynamics in a financial market with heterogeneous agents," Journal of Economic Dynamic \& Control, vol.30, 2006, pp.1755-1786.

[5]Harrison Hong, Jose Scheinkman, Wei Xiong, "Asset Float and Speculative Pubbles," The Journal of Finance, vol 3, 2006.

[6] H.Peter Boswijk, Cars H. Hommes, Sebastiano Manzan, "Behavioral heterogeneity in stock prices," Journal of Economic Dynamic \& Control, vol.31, 2007, pp.1938-1970. 
[7] R.Cross, M.Grinfeld, H.Lamba, T.Seaman, "Stylized facts from a threshold-based heterogeneous agent model," Eur. Phys. J. B, vol.57, 2007, pp.213-218.

[8] Roger, Patrick, "Does the Consciousness of the Disposition Effect Increase the Equity Premium," Journal of Behavioral Finance, vol.10, 2009, pp.138-151.

[9] Barberis, N., Huang, M., Santos, T, "Prospect theory and asset prices," Quarterly Journal of Economics, 2001, pp. 1-53.

[10] Wenlang Zhang, Willi Semmler., "Prospect theory for stock markets: Empirical evidence with time-series data," Journal of Economic Behavior \& Organization, vol.72, 2009, pp.835-849.

[11] Leigh Tesfatsion, Kennethl.Judd, "Heterogeneous agent models in economics and finance," Handbook of computational economics, Vol.2, pp.1109-1186. 